\title{
QUEM ESTÁ PAGANDO JUROS SOBRE CAPITAL PRÓPRIO NO BRASIL?*
}

\author{
WHO IS PAYING INTERESTS ON OWN CAPITAL IN BRAZIL?
}

\author{
ARIOVALDO DOS SANTOS \\ Professor Titular do Departamento de Contabilidade e Atuária \\ da Faculdade de Economia, Administração e Contabilidade \\ da Universidade de São Paulo - Campus Capital \\ E-mail: arisanto@usp.br
}

\section{RESUMO}

A partir da promulgação da Lei 9.249/95, foi a criada possibilidade de as empresas remunerarem seus acionistas através do pagamento de "Juros Sobre o Capital Próprio - JSCP". Tal lei permite que os pagamentos efetuados a esse título sejam considerados como despesas dedutíveis no cálculo do imposto de renda e da contribuição social incidentes sobre os lucros das empresas. Essa inovação fiscal veio acompanhada de duas outras importantes novidades: a) redução da alíquota básica e dos adicionais de imposto de renda incidentes sobre os lucros das empresas; b) eliminação dos efeitos da inflação nas demonstrações contábeis. A pesquisa realizada é inédita no Brasil e proporcionou a possibilidade de se conhecer qual foi a atitude das empresas no que se refere à utilização da legislação relativa aos JSCP, além de buscar respostas para as seguintes questões: a) as empresas estão pagando aos seus sócios/acionistas juros sobre o capital próprio? b) quem está pagando mais JSCP: indústria, comércio ou serviços? c) as empresas nacionais pagam mais JSCP do que as estrangeiras? d) e as companhias abertas pagaram mais JSCP do que as fechadas? Foram avaliadas as publicações de aproximadamente 3.000 empresas que atuam em todas as áreas do território nacional e que estejam enquadradas dentro das seguintes características: a) tenham divulgado as demonstrações contábeis através dos meios de comunicação; b) estejam classificadas dentro das atividades de prestação de serviiços, excluindo-se o setor financeiro, comercial e industrial; c) adotem como forma de tributação o lucro real, uma vez que, regra geral, aquelas que se utilizam de outras formas de tributação não podem se valer da prerrogativa de considerar como despesas operacionais os valores pagos a título de JSCP. O resultado demonstrou que $40 \%$ das empresas pesquisadas têm utilizado a alternativa do pagamento ou crédito aos seus sócios e acionistas na forma de JSCP. Também ficou evidenciado que a distribuição entre as empresas industriais, comerciais e prestadoras de serviços é bastante equilibrada. Outra constatação importante está relacionada ao acréscimo de empresas estatais que passaram a pagar aos seus acionistas os JSCP.

Palavras-chave: Juros Sobre o Capital Próprio - JSCP; Lei 9.249/95; Custo de oportunidade; Inflação.

\section{ABSTRACT}

The publication of Law 9.249/95 created the possibility for companies to reward their stockholders by paying "Interest on Own Capital - IOC". This Law allows these payments to be considered as deductible expenses when calculating income and social contribution taxes. This fiscal innovation was accompanied by two other important novelties: a) reduction of basic and additional income tax rates charged on company profits; $b$ ) elimination of inflation effects from financial statements. This study, unpublished in Brazil, made it possible to know companies' attitudes about using IOC legislation, and attempted to answer the following questions: a) are companies paying interest on own capital to their partners / stockholders? b) Which sector pays more IOC: industry, trade or services? c) Do Brazilian companies pay more IOC than foreign enterprises? d) Do publicly-traded companies pay more IOC than private companies? We assessed the publications of approximately 3,000 companies from all over Brazil, which attended to the following characteristics: a) published their financial statements in the media; $b$ ) are classified as industry, trade or service companies, excluding the financial sector; c) adopt real profit as a taxation base since, in general, companies using other bases of taxation cannot consider IOC payments as operational expenses. The result demonstrated that $40 \%$ of the companies have used IOC as a partner and stockholder payment or credit alternative. It was also found the existence of a rather balanced distribution among industrial, trade and service companies. Another important observation regards the increased number of public companies that started paying IOC to their stockholders.

Keywords: Interest on Own Capital; Law 9.249/95; Opportunity Cost; Inflation. 


\section{INTRODUÇÃO}

1994 foi um ano em que mais um plano econômico foi colocado em prática. Tratava-se do Plano Real que, ao contrário dos outros planos implantados a partir dos anos oitenta, não vinha com congelamentos de preços, tablitas, confiscos de contas correntes e poupanças, controle de preços etc. Sua implantação foi realizada em duas fases distintas. A primeira delas ocorreu com a criação da Unidade Real de Valor - URV a partir de março. Nessa fase, todos os valores da economia e dos contratos que estavam em vigor naquele instante foram transformados nesse novo índice da economia. Convém lembrar que a URV não era uma nova moeda, mas sim uma espécie de índice que foi utilizado como conversor da moeda.

A segunda fase do Plano Real veio com a transformação da moeda e isso ocorreu em julho de 1994. Independentemente das análises, contra ou a favor, que se possa fazer dos resultados de tal plano, uma coisa é indiscutível: nossos níveis de inflação tiveram reduções bastante significativas e muito mais duradouras do que as atingidas em planos anteriores. Em junho de 1994, a taxa de inflação mensal chegava à casa dos $50 \%$, enquanto no segundo semestre desse ano a média mensal foi de 2,9\%. Outro dado que não pode ser esquecido é que essa variação de preços do segundo semestre de 1994 estava contaminada por parte das variações de preços de maio e junho, refletidas somente nos meses subseqüentes. Isso significa que - país voltava a experimentar taxas de inflação que havia vivido no final dos anos 1960 e início dos anos 1970. No primeiro semestre de 1995, esse índice médio mensal foi de 1,7\%. Óbvio que um índice de 1,7\% de inflação mensal pode ser considerado extremamente alto, mas para um país que tinha vivido os últimos 25 anos com taxas médias sempre muito mais elevadas do que essa, os resultados podiam ser considerados como muito bons.

A lógica central do Plano Real fundamentou-se no ataque ao que se convencionou chamar de inflação inercial e proibiu as atualizações monetárias automáticas de todos os tipos de contratos, inclusive os de aluguéis e de trabalho. Após mais de uma década de sua implantação, o Plano Real demonstrou ser bastante eficaz no combate à inflação. Po- rém, deve-se ressalvar que, mesmo com todos os méritos que o Plano Real possa ter demonstrado, uma coisa é certa, a inflação foi bastante reduzida mas não foi eliminada. A Tabela 10 demonstra isso de forma inequívoca.

Em 31 de agosto de 1995, o Ministro da Fazenda encaminhou a Exposição de Motivos no 325/MF relativa a Projeto de Lei que, posteriormente, foi transformada na Lei 9.249/95. O item 2 da referida Exposição de Motivos afirma:

A reforma objetiva simplificar a apuração do imposto, reduzindo as vias de planejamento fiscal, uniformizar o tratamento tributário dos diversos tipos de renda, integrando a tributação das pessoas jurídicas, ampliar o campo de incidência do tributo, com vistas a alcançar os rendimentos auferidos no exterior por contribuintes estabelecidos no País e, finalmente, articular a tributação das empresas com o Plano de Estabilização Econômica. (grifo do autor)

Mesmo não tendo eliminado completamente o processo inflacionário, em dezembro de 1995, com o objetivo de suprimir de vez a cultura da memória inflacionária, foi editada a Lei 9.249, com vigência a partir de janeiro de 1996 , que em seus artigos $4^{\circ}$ e $5^{\circ}$ determina:

Art. 4 - Fica revogada a correção monetária das demonstrações financeiras de que tratam a Lei no 7.799, de 10 de julho de 1989, e o art. Io da Lei no 8.200, de 28 de junho de 1991.

Parágrafo único. Fica vedada a utilização de qualquer sistema de correção monetária de demonstrações financeiras, inclusive para fins societários. (grifo do autor)

Como se percebe do texto legal, a proibição de utilização de sistemas que possam considerar os efeitos da inflação não é restrita a aspectos fiscais, mas inclui também os aspectos societários. Isso significa que a perda do poder de compra da moeda não só não deve ser considerada no cálculo dos impostos (imposto de renda da pessoa jurídica e contribuição social sobre o lucro), como também para efeito dos dividendos. Dessa forma, a legislação impediu qualquer

Tabela 1 Variações acumuladas da inflação (percentuais)

\begin{tabular}{c|c|c|c|c|c|c|c|c|c|c|c|c|c|c} 
Índices & $\begin{array}{c}\text { Jul } \mathbf{9 4} \text { a } \\
\text { dez/94 }\end{array}$ & $\mathbf{1 9 9 5}$ & $\mathbf{1 9 9 6}$ & $\mathbf{1 9 9 7}$ & $\mathbf{1 9 9 8}$ & $\mathbf{1 9 9 9}$ & $\mathbf{2 0 0 0}$ & $\mathbf{2 0 0 1}$ & $\mathbf{2 0 0 2}$ & $\mathbf{2 0 0 3}$ & $\mathbf{2 0 0 4}$ & $\mathbf{2 0 0 5}$ & $\mathbf{2 0 0 6}$ & $\begin{array}{c}\text { Acum. 96 a } \\
\text { Dez/2006 }\end{array}$ \\
$\begin{array}{c}\text { IGP-M } \\
\text { (FGV) }\end{array}$ & $16,52 \%$ & $15,24 \%$ & $9,19 \%$ & $7,74 \%$ & $1,79 \%$ & $20,10 \%$ & $9,95 \%$ & $10,38 \%$ & $25,31 \%$ & $8,71 \%$ & $12,41 \%$ & $1,21 \%$ & $3,83 \%$ & $180,88 \%$ \\
\hline $\begin{array}{c}\text { INPC } \\
\text { (IBGE) }\end{array}$ & $19,81 \%$ & $21,98 \%$ & $9,12 \%$ & $4,34 \%$ & $2,49 \%$ & $8,43 \%$ & $5,27 \%$ & $9,44 \%$ & $14,74 \%$ & $10,38 \%$ & $6,13 \%$ & $5,05 \%$ & $2,81 \%$ & $111,63 \%$ \\
\hline $\begin{array}{c}\text { IPCA } \\
\text { (IBGE) }\end{array}$ & $18,44 \%$ & $22,41 \%$ & $9,56 \%$ & $5,22 \%$ & $1,66 \%$ & $8,94 \%$ & $5,97 \%$ & $7,67 \%$ & $12,53 \%$ & $9,30 \%$ & $7,60 \%$ & $5,69 \%$ & $3,14 \%$ & $110,19 \%$ \\
\hline $\begin{array}{c}\text { IGP-DI } \\
\text { (FGV) }\end{array}$ & $18,17 \%$ & $14,71 \%$ & $9,36 \%$ & $7,49 \%$ & $1,71 \%$ & $19,99 \%$ & $9,81 \%$ & $10,40 \%$ & $26,41 \%$ & $7,67 \%$ & $12,14 \%$ & $1,22 \%$ & $3,79 \%$ & $178,88 \%$ \\
\hline
\end{tabular}


possibilidade de as empresas buscarem, através de suas assembléias de acionistas, mecanismos legais para cálculo e pagamento de dividendos a partir de resultados que considerem os efeitos da perda de poder aquisitivo da moeda.

Outra grande novidade, do ponto de vista fiscal, incluída nessa Lei 9.249/95, foi a criação da possibilidade de as empresas passarem a remunerar, através do pagamento de juros, como despesas dedutíveis para o cálculo do imposto de renda e da contribuição social, o capital dos acionistas. A faculdade desse pagamento está prevista no artigo 9․, que prevê:

A pessoa jurídica poderá deduzir, para efeitos da apuração do lucro real, os juros pagos ou creditados individualizadamente a titular, sócios ou acionistas, a título de remuneração do capital próprio, calculados sobre as contas do patrimônio líquido e limitados à variação, pro rata dia, da Taxa de Juros de Longo Prazo - TJLP.

Na fundamentação para a introdução dessa nova forma de remunerar o acionista, o Ministro da Fazenda, no item 10 de sua Exposição de Motivos, justificou:

Com vistas a equiparar a tributação dos diversos tipos de rendimentos do capital, o Projeto introduz a possibilidade de remuneração do capital próprio investido na atividade produtiva, permitindo a dedução dos juros pagos ao acionista, até o limite da variação da Taxa de Juros de Longo Prazo - TJLP.

Deve-se ressalvar que, apesar de sua difusão no Brasil ter acontecido a partir da Lei 9.249/95, a figura dos Juros sobre o Capital no Brasil já havia sido incluída na Lei 6.404/76.

Referida Lei, em seu artigo 179, prevê o seguinte:

As contas serão classificadas do seguinte modo:

$1-[\ldots]$

$\checkmark$ - no ativo diferido: as aplicações de recursos em despesas que contribuirão para a formação do resultado de mais de um exercício social, inclusive os juros pagos ou creditados aos acionistas durante o período que anteceder o início das operações sociais. (grifo do autor)

Como se pode perceber desse texto legal, a permissão para a contabilização de remuneração atribuída aos acionistas a título de juros estava restrita aos valores pagos no período que antecedesse ao início das operações. Tal possibilidade acabava por abranger apenas investimentos que tivessem prazos de maturação mais longos e isso, praticamente, restringia a utilização desses "juros" às empresas concessionárias de serviços públicos, mais especificamente aquelas que desenvolviam suas operações nas aéreas de energia elétrica, saneamento básico e telecomunicações.

Muitas dessas empresas, principalmente as de saneamento básico e de energia elétrica, adotaram essa prática de contabilização visando dois aspectos específicos: o primeiro por recomendação do Departamento Nacional de Águas e Energia Elétrica - DNAEE, e o segundo por interesses econômicos, uma vez que a base para cálculos das tarifas, que durante muito tempo foram controladas pelo Governo, considerava o valor total do ativo permanente, portanto, incluindo os valores contabilizados como ativo diferido.

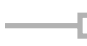

\section{ANTECEDENTES E JUSTIFICATIVAS}

Os diversos conceitos utilizados para juros sobre o capital próprio têm suas raízes calcadas nos conceitos econômicos de custo de oportunidade.

A literatura econômica internacional tem consagrado, através dos tempos, diversas definições e exemplos relativos a custo de oportunidade. Lipsey e Steiner, quando tratam de Custo de Oportunidade, assim se manifestam:

O custo de se utilizar alguma coisa num empreendimento específico é o benefício sacrificado (ou o custo de oportunidade) por não utilizá-lo no seu melhor uso alternativo. (LIPSEY E STEINER, 1969, p. 215).

Também a literatura contábil internacional, ao longo do tempo, tem dado especial atenção ao assunto. Atkinson, Banker, Kaplan e Young, no capítulo que trata de "Decisões sobre Preços e Mix de Produtos", do livro de Contabilidade Gerencial, apresentam a seguinte definiçãa para Custo de Oportunidade:

Quantia de lucro perdido quando a oportunidade proporcionada por uma alternativa é sacrificada pela escolha de outra. (ATKINSON et alii, 2000, p. 365).
Da literatura contábil nacional, pode-se extrair do texto publicado por Martins, em exemplo bastante didático, o significado cristalino do que deve ser entendido por Custo de Oportunidade.

Custo de Oportunidade significa o quanto alguém deixou de ganhar por ter adotado uma alternativa em vez de outra, ou seja, se alguém escolheu investir em uma fábrica de giz, deixando de, com isso, investir na construção de um supermercado, que era a segunda melhor alternativa existente na época, diz-se que o Custo de Oportunidade da decisão de investir na fábrica de giz é o quanto se deixou de ganhar por não se construir o supermercado.(MARTINS, 1996, p. 433).

O tema "Juros Sobre o Capital Próprio" pode ser pesquisado sobre diversos ângulos. Por exemplo, no dia-a-dia das empresas e em muitos trabalhos escritos, a expressão "juros sobre o capital próprio" tem sido utilizada como algo que substitui o "custo do capital próprio" ou "custo de oportunidade", e a utilização dessas expressões como sinônimas pode não ser a mais adequada. 
Na literatura econômica e mesmo na contábil, como visto, a definição de "custo de oportunidade" vem sempre atrelada à hipótese de melhor alternativa que foi deixada de lado ou desprezada. Isso pressupõe que a aplicação de tal conceito exigirá a existência de duas ou mais alternativas possíveis, e que sejam excludentes. Óbvio, se não houver uma segunda alternativa viável não se poderá falar em "custo de oportunidade".

O "custo do capital próprio", normalmente, é definido pelo retorno que é esperado pelos investidores (sócios ou acionistas) em relação aos recursos por eles aplicados em determinados empreendimentos. Quando se fala da apuração do custo dos capitais de terceiros parece não haver grandes especulações ou discordâncias a respeito; afinal, as taxas são fixadas e facilmente mensuráveis através dos recursos de informação de que dispõe a contabilidade. Já para a mensuração do custo do capital próprio não existe consenso. Para citar uma das discordâncias existentes, pode-se dizer que, mesmo o valor do capital próprio a ser utilizado para a referida mensuração, não é consensual, pois há uma intensa discussão a respeito se devem ou não ser incluídos, nesse capital, os resultados do próprio período.

Outro aspecto bastante discutido, à época em que o Projeto de Lei 913/95 acabou por se transformar na Lei 9.249/95, foi o relativo à supressão do reconhecimento da inflação nas demonstrações contábeis. Sabia-se que o Plano Real, mesmo tendo conseguido reduzir, não eliminaria por completo o processo inflacionário do país. A demonstração clara dessa assertiva pode ser constatada pelos dados da Tabela 1 que apresenta os índices oficiais de inflação, anual e acumulada; O IPCA, calculado pelo Instituto Brasileiro de Geografia e Estatística - IBGE, acumulou, no período de julho/1994 a dezembro/2006, variação de preços de $205 \%$. Se for tomada a inflação acumulada no período de janeiro de 1996, início da vigência da Lei 9.249/95, até dezembro de 2006, últimas demonstrações contábeis que serão utilizadas nesta pesquisa, tem-se 110,19\%.

Também é bastante conhecido que os efeitos inflacionários acabam por atingir diferentemente as empresas. Sabe-se que as estruturas de capitais são fatores determinantes nos cálculos de ganhos ou perdas com a inflação. Exemplificando, a estrutura de capitais das empresas de energia elétrica, cujos ativos permanentes (principalmente, terrenos, edificações, máquinas, equipamentos, linhas de transmissão etc.) representam, normalmente, valores superiores a $90 \%$ do ativo total (10\% para outros ativos), não pode ser comparada à estrutura de capitais das instituições financeiras ou comerciais varejistas, nas quais essa relação é praticamente inversa.

A Lei 9.249/95, que possibilitou, para efeitos fiscais, a dedutibilidade dos valores pagos ou creditados a título de Juros Sobre o Capital Próprio, estabelece as seguintes regras:

1. A pessoa jurídica poderá considerar como despesa operacional e, conseqüentemente, deduzir na determinação do lucro real, observado o regime de competência, o montante dos juros pagos ou creditados individualizadamente a titular, sócios ou acionistas, a título de remuneração do capital próprio, calculados sobre as contas do patrimônio líquido e limitados à variação pro rata dia da Taxa de Juros de Longo Prazo (TJLP).

2. Referido montante remuneratório do capital para que possa ser integralmente dedutível como despesa operacional não poderá ultrapassar: a) cinqüenta por cento do lucro líquido do período de apuração a que corresponder o pagamento ou crédito dos juros, após a dedução da contribuição social sobre o lucro líquido e antes da provisão para o imposto de renda e da dedução dos referidos juros; ou b) cinqüenta por cento dos saldos de lucros acumulados e reservas de lucros.

Deve-se observar que no cálculo da remuneração deverão ser excluídos do patrimônio líquido os valores de reserva de reavaliação e da reserva especial relativa à correção monetária especial apurada de acordo com as regras estabelecidas no Decreto 332/91. Tais valores só não serão excluídos se já tiverem sido considerados no cálculo do lucro real. Há, ainda, que se observar que os juros pagos ou creditados poderão ser compensados com o valor dos dividendos obrigatórios a que têm direito os acionistas.

Em relação à tributação dos JSCP (Juros Sobre o Capital Próprio), pagos ou creditados às pessoas físicas ou jurídicas, a legislação estabelece que haverá incidência do imposto de renda na fonte à alíquota de $15 \%$. Para as pessoas físicas, o valor do imposto é considerado como tributação exclusiva na fonte. Para as pessoas jurídicas, que têm seus resultados tributados com base no lucro real, o valor dos juros deve ser considerado como receita financeira e o imposto de renda retido na fonte é tratado como antecipação do imposto devido no encerramento do exercício. Para as empresas que optaram pela tributação de seus resultados através do lucro presumido ou arbitrado, os juros recebidos integram a base de cálculo do imposto de renda e o imposto retido na fonte também será considerado como antecipação do imposto devido. No caso das pessoas jurídicas imunes não há incidência do imposto quando do pagamento ou crédito; nas pessoas jurídicas isentas, o tratamento é semelhante às pessoas físicas, ou seja, o imposto é considerado como tributação exclusiva na fonte.

A legislação ainda prevê que, à opção da pessoa jurídica, os juros sobre o capital próprio poderão ser mantidos em conta específica de reserva de lucro para ser utilizada em futuros aumentos de capital. Nessa hipótese, tal valor poderá ser considerado no cálculo do lucro real, desde que a pessoa jurídica assuma o pagamento do imposto de renda equivalente ao que seria descontado na fonte, caso o pagamento tivesse sido efetuado diretamente aos acionistas.

Em trabalho publicado sobre a história dos juros sobre o capital próprio, quando da apresentação de suas conclusões, Martins afirma:

A figura dos Juros sobre o Capital Próprio veio para tentar reduzir uma iniqüidade fiscal muito séria criada 
com a extinção da correção monetária dos balanços. Não se trata de uma benesse ou de uma liberalidade gratuita por parte do Governo, mas de uma tentativa (ra- zoavelmente bem sucedida, reconheça-se) de redução dessa iniqüidade comentada. (MARTINS, 2004, p. 6).

\section{A PESQUISA}

\subsection{Questões a serem respondidas}

No Brasil, uma das principais reclamações dos pesquisadores da área de Ciências Contábeis é a total indisponibilidade de dados para a realização de pesquisas empíricas. As bases de dados disponíveis ou não são completas ou não podem ser acessadas. Por exemplo, a base de dados da Receita Federal é extraordinária, mas, sob a argumentação de que os dados estão protegidos por sigilo fiscal, não se pode dela usufruir.

A presente pesquisa é absolutamente inédita em nosso País e tratou de conhecer se as empresas estão utilizando a legislação relativa aos JSCP. Assim, a pesquisa buscou respostas para as seguintes questões:

- As empresas estão pagando aos seus sócios/acionistas juros sobre o capital próprio - JSCP?

- Quem está pagando mais JSCP: indústria, comércio ou serviços?

- Quais empresas pagam mais JSCP: nacionais, estrangeiras ou estatais?

- As companhias abertas pagam mais JSCP do que as fechadas?

\subsection{Planejamento da pesquisa e coleta de dados}

A observação é praticamente uma constante na atividade humana. Continuamente, estão sendo feitas observações. O dia-a-dia é repleto de observações, desde quando se acorda até o momento de dormir, no caminho para o trabalho ou para a escola, dentro de um ônibus ou de um automóvel, assistindo ou praticando qualquer esporte etc. Enfim, está-se sempre observando o mundo que está à nossa volta. A esse respeito, vale destacar:

a observação não apenas é uma das atividades mais difusas da vida diária; é também um instrumento básico da pesquisa científica. A observação se torna uma técnica científica na medida em que serve a um objetivo formulado de pesquisa; é sistematicamente planejada; é sistematicamente registrada e ligada a proposições mais gerais em vez de ser apresentada como conjunto de curiosidades interessantes; é submetida a verificações e controles de validade e precisão. (SELLTIZ, 1974, p. 225).

Isso significa que uma grande quantidade de dados, muitos dos quais poderão ser utilizados como provas de uma pesquisa, podem ser obtidos através do que se convencionou chamar de observação. Óbvio que essa é apenas uma das formas pela qual qualquer cientista, principalmente dentro das áreas sociais, poderá conseguir dados para suas investigações.
Entrevistas, questionários, utilização de métodos quantitativos nas técnicas de projeção e levantamento de eventuais registros a respeito do assunto que se está pesquisando poderão completar e substituir as necessidades de observações efetuadas diretamente pelo pesquisador. Ainda, do ponto de vista conceitual, a coleta de dados, também, poderá ser procedida através de materiais que a própria sociedade cria para detalhar e informar a respeito de suas próprias atividades. Essa forma de transmissão de informações é chamada, nas pesquisas de relações sociais, de comunicações de massa.

Poder-se-iam enquadrar os conjuntos de demonstrações contábeis produzidos e divulgados pelas empresas dentro dessa categoria de comunicações de massa, principalmente porque não foram criados para o pesquisador e, portanto, livre de sua interferência ou viés conceitual. Esse conjunto de informações proporciona ao pesquisador a possibilidade de um conhecimento histórico, tanto em relação ao passado como da sociedade atual.

\subsection{População, amostra e caracterização da população}

Nesse item, será de extrema importância fixarem-se os conceitos de população e de amostra para que se possa nortear e compreender o trabalho de pesquisa a ser realizado. A parcela de determinado grupo é denominada amostra, enquanto o grupo a que pertence ou de onde se extrai a amostra é denominado população. Os elementos de uma população podem ser pessoas, animais, árvores, produtos manufaturados, mercadorias, alturas e pesos das pessoas etc.

Tratando de diferenciar população e amostra, podem-se destacar

Os termos 'população' e 'amostra' se referem a um conjunto específico de circunstâncias. Ou seja, em determinado caso os alunos de uma sala de aula podem ser considerados como uma população, da qual iremos extrair amostras para análise. Já em outra situação, aqueles mesmos alunos podem ser considerados como uma amostra de todos os alunos do colégio, ou de toda a universidade. Como o propósito da amostragem é fazer generalizações sobre a população básica, é axiomático que a 'população alvo' seja estabelecida de modo que se possam fazer generalizações válidas. (STEVENSON, 1981, p. 159).

As populações são, via de regra, classificadas em finitas e infinitas, e, como o próprio nome indica, as populações finitas são aquelas de tamanho limitado. Por exemplo: as populações de uma cidade, de um estado ou de um país; a quantidade de pessoas de um ginásio de esportes; a quantidade de automóveis estacionados no pátio de um 
supermercado; a quantidade de empregados de uma fábrica etc. Por outro lado, as populações infinitas são aquelas de tamanho ilimitado. Exemplos de populações infinitas: quantidade de observações relativas ao comportamento das pessoas; quantidade de vezes que a porta de um carro pode ser aberta e fechada; quantidade de sorteios que se pode fazer através das cartas de um baralho etc.

Para amostra utilizar-se-á o ensinamento de Toledo e Ovalle, que afirmam:

$A$ amostra pode ser definida como um subconjun-

to, uma parte selecionada da totalidade de observações abrangidas pela população, através da qual se faz um juízo ou inferência sobre as características da população. (TOLEDO e OVALE, 1989, p. 17).

Ainda sobre amostra, Martins (1994, p. 38-39) classifica os métodos para composição da amostra em probabilístico e não probabilístico ou intencional e apresenta a seguinte divisão: probabilísticos - amostragem aleatória simples, amostragem sistemática, amostragem estratificada e amostragem por conglomerados; não probabilísticos - amostragem acidental, amostragem intencional e amostragem por quotas.

A respeito dos métodos não probabilísticos, destacam-se:

São amostragens em que há uma escolha delibera-

da dos elementos da amostra. Não é possível generalizar os resultados das pesquisas para a população, pois as amostras não-probabilísticas não garantem a representatividade da população. (MARTINS, 1994, p. 40).

No que se refere às empresas, em atividade ou já encerradas, o Brasil não dispõe de dados que possam ser utilizados como fonte inequívoca de pesquisa para qualquer tipo de trabalho. O que habitualmente se encontra são previsões, expectativas, estimativas, valores aproximados etc. Assim, esta pesquisa teve como base fundamental o cadastro de empresas mantido pela Fundação Instituto de Pesquisas Contábeis, Atuariais e Financeiras - FIPECAFI, ligada ao Departamento de Contabilidade e Atuária da Faculdade de Economia, Administração e Contabilidade da Universidade de São Paulo. Esse cadastro é a principal base de dados utilizada na elaboração da edição anual de Me-

\section{Ihores e Maiores, da revista Exame - Editora Abril.}

Desse cadastro constam aproximadamente $3.000 \mathrm{em}$ presas que atuam em todas as áreas do território nacional. As informações do cadastro são, regra geral, obtidas a partir de demonstrações contábeis publicadas em jornais de grande circulação, nos Diários Oficiais de todas as Unidades da Federação, além de questionários que são preenchidos pelas próprias empresas

Como se sabe, nem todas as empresas que atuam no Brasil, infelizmente, têm obrigação de publicar demonstrações contábeis; tal obrigação está restrita às empresas constituídas na forma jurídica de sociedades por ações. Assim, para as empresas formadas sob outras formas jurídicas, como, por exemplo, as companhias limitadas, sociedades civis etc., nada é exigido no que se refere à divulgação de suas informações. Contudo, muitas empresas, cientes da responsabilidade social que têm, fazem divulgações espontâneas e participam da pesquisa que anualmente a FIPECAFI realiza, enviando as informações necessárias. Assim, o referido cadastro conta com informações de Balanço e Demonstração de Resultados de mais de duas centenas de sociedades por quotas de responsabilidade limitada. Tal base de dados engloba as demonstrações contábeis do período de 1995 a 2005. Como o pagamento de juros sobre o capital próprio passou a vigorar a partir do exercício de 1996, pode-se afirmar que se considerou todo o período em que tal prática vem sendo adotada.

As empresas pesquisadas foram agrupadas pelo ramo de atividade: empresas industriais, comerciais e prestadoras de serviços, excluindo-se as do setor financeiro. Outra forma de agrupamento foi pela origem do capital. Nesse conjunto, segregaram-se as empresas nacionais, estrangeiras e estatais. Como nacionais foram consideradas aquelas cujos acionistas controladores são pessoas físicas ou jurídicas residentes ou domiciliadas no Brasil. Da mesma forma, considerou-se empresa estrangeira aquela que é controlada por pessoas físicas ou jurídicas residentes ou domiciliadas no exterior. Empresas controladas por pessoas jurídicas nacionais, cujo controle central, como em muitos casos é sabido, esteja no exterior, foram consideradas estrangeiras. As estatais são aquelas que são controladas pelos governos Federal, Estaduais ou Municipais. Outra forma de aglutinação foi entre companhias abertas e fechadas, e para isso foi utilizada a mesma identificação feita pelo próprio mercado, isto é, as empresas cujos títulos são negociados em Bolsa de Valores ou aquelas que se endividaram através de venda de debêntures foram consideradas abertas. As demais são fechadas.

\subsection{Apuração e análise dos dados}

A população do estudo considerou aproximadamente 3.000 empresas que atuam no território nacional e que apresentaram as seguintes características: a) tenham divulgado demonstrações contábeis através dos meios de comunicação ou apresentado, de forma espontânea, as demonstrações para a pesquisa de Melhores e Maiores, independentemente da forma jurídica de constituição; b) estejam classificadas como empresas comerciais, industriais ou de prestação de serviços, não incluindo empresas do setor financeiro; c) empresas que adotam como forma de tributação o lucro real, uma vez que aquelas que utilizam outra forma de tributação não podem se valer da prerrogativa de considerar como despesas operacionais os valores pagos a título de JSCP. Dentre as empresas pesquisadas, existem companhia abertas, fechadas e limitadas, isto é, nas quais a divisão do capital é feita por quotas e não por ações.

Para se ter uma melhor forma de avaliação comparativa, todos os valores apresentados como resultado da pesquisa foram atualizados, com base no IGP-M da FGV, para moeda de dezembro de 2005. Após essa atualização, os valores encontrados foram convertidos pela taxa do dólar de dezembro de 2005, evitando-se, assim, os vieses que as 
mudanças cambiais poderiam produzir.

Feitas as avaliações descritas anteriormente e considerando-se, para efeito deste trabalho, apenas as empresas que apuram o imposto de renda da pessoa jurídica e contribuição social sobre o lucro através da sistemática denominada pela Secretaria da Receita Federal de "Lucro Real", a Tabela 20 apresenta o conjunto de demonstrações contábeis utilizado.

Apesar de parecer óbvio, neste trabalho utilizou-se o conjunto das empresas que tiveram lucro, pois se constatou que algumas das empresas pesquisadas, mesmo tendo prejuízos, optaram por pagar aos seus sócios/acionistas JSCP. Esse tipo de procedimento, apesar de incomum, está mencionado na legislação que prevê o pagamento dos JSCP até o limite máximo do lucro do exercício ou dos lucros acumulados.

Dentre as diversas alternativas disponíveis para a segregação e análise dos dados relativos ao pagamento ou crédito de juros sobre o capital próprio, conforme dito anteriormente, foram escolhidas 3 e são as seguintes:
- empresas com e sem ações negociadas em Bolsa de Valores;

- empresas nacionais, estrangeiras e estatais e

- empresas industriais, comerciais e prestadoras de serviços.

Na seqüência, são apresentadas as Tabelas 3 a 5, com as respectivas análises, de acordo com a segregação anteriormente descrita.

Como se pode constatar na Tabela $3 \mathbf{O}$, no primeiro ano de vigência da legislação que autorizou o pagamento ou crédito de juros sobre o capital próprio não houve grande adesão por parte das empresas. De um total de 493, apenas 61 empresas exerceram a opção desse pagamento.

Em 1996, dentre as 97 empresas pesquisadas no grupo das que negociam suas ações na Bolsa de Valores, apenas 13 pagaram a referida remuneração aos seus acionistas. $O$ volume desses pagamentos atingiu o equivalente a 657,6 milhões de dólares, em moeda de poder aquisitivo de de-

Tabela 2 | Empresas que apuraram seus impostos com base no Lucro Real

\begin{tabular}{c|c|c|c} 
ANO & TOTAL DE EMPRESAS & EMPRESAS COM LUCRO & EMPRESAS COM PREJUÍZO \\
\hline 1996 & 650 & 493 & 157 \\
\hline 1997 & 708 & 535 & 173 \\
\hline 1998 & 800 & 586 & 214 \\
\hline 1999 & 927 & 599 & 328 \\
\hline 2000 & 996 & 724 & 272 \\
\hline 2001 & 1.029 & 735 & 294 \\
\hline 2002 & 1.106 & 744 & 362 \\
\hline 2003 & 1.161 & 924 & 237 \\
\hline 2004 & 1.193 & 997 & 196 \\
\hline 2005 & 1.130 & 955 & 175
\end{tabular}

Tabela 3 Empresas com e sem ações na Bolsa de Valores

Empresas cuja forma de tributação = Lucro Real

em US\$ milhões - 31/12/2005

\begin{tabular}{|c|c|c|c|c|c|c|c|c|c|c|c|c|}
\hline \multirow{3}{*}{ Ano } & \multicolumn{4}{|c|}{ Com ações na Bolsa } & \multicolumn{4}{|c|}{ Sem ações na Bolsa } & \multicolumn{4}{|c|}{ Total } \\
\hline & \multirow{2}{*}{$\begin{array}{l}\text { Quanti- } \\
\text { dade de } \\
\text { empresas } \\
\text { c/ lucro }\end{array}$} & \multicolumn{3}{|c|}{$\begin{array}{l}\text { Informações sobre } \\
\text { empresas que pagaram/ } \\
\text { creditaram JSCP }\end{array}$} & \multirow{2}{*}{$\begin{array}{l}\text { Quanti- } \\
\text { dade de } \\
\text { empresas } \\
\text { c/ lucro }\end{array}$} & \multicolumn{3}{|c|}{$\begin{array}{c}\text { Informações sobre } \\
\text { empresas que pagaram/ } \\
\text { creditaram JSCP }\end{array}$} & \multirow{2}{*}{$\begin{array}{l}\text { Quanti- } \\
\text { dade de } \\
\text { empresas } \\
\text { c/ lucro }\end{array}$} & \multicolumn{3}{|c|}{$\begin{array}{l}\text { Informações sobre } \\
\text { empresas que pagaram/ } \\
\text { creditaram JSCP }\end{array}$} \\
\hline & & $\begin{array}{l}\text { Quanti- } \\
\text { dade de } \\
\text { empresas }\end{array}$ & $\%$ & $\begin{array}{c}\text { US\$ } \\
\text { milhões }\end{array}$ & & $\begin{array}{c}\text { Quanti- } \\
\text { dade de } \\
\text { empresas }\end{array}$ & $\%$ & $\begin{array}{c}\text { US\$ } \\
\text { milhões }\end{array}$ & & $\begin{array}{l}\text { Quanti- } \\
\text { dade de } \\
\text { empresas }\end{array}$ & $\%$ & $\begin{array}{c}\text { US\$ } \\
\text { milhões }\end{array}$ \\
\hline 1996 & 97 & 13 & 13,4 & 657,6 & 396 & 48 & 12,1 & 442,1 & 493 & 61 & 12,4 & $1.099,7$ \\
\hline 1997 & 95 & 37 & 38,9 & $1.992,9$ & 440 & 102 & 23,2 & $1.196,3$ & 535 & 139 & 26,0 & $3.189,2$ \\
\hline 1998 & 103 & 49 & 47,6 & $4.129,8$ & 483 & 157 & 32,5 & $1.525,8$ & 586 & 206 & 35,2 & $5.655,6$ \\
\hline 1999 & 94 & 46 & 48,9 & $2.781,1$ & 505 & 162 & 32,1 & $1.022,3$ & 599 & 208 & 34,7 & $3.803,4$ \\
\hline 2000 & 124 & 67 & 54,0 & $4.905,9$ & 600 & 222 & 37,0 & $1.547,3$ & 724 & 289 & 39,9 & $6.453,2$ \\
\hline 2001 & 104 & 64 & 61,5 & $4.396,6$ & 631 & 238 & 37,7 & $1.752,8$ & 735 & 302 & 41,1 & $6.149,4$ \\
\hline 2002 & 86 & 56 & 65,1 & $2.974,3$ & 658 & 264 & 40,1 & $1.404,2$ & 744 & 320 & 43,0 & $4.378,5$ \\
\hline 2003 & 116 & 72 & 62,1 & $4.742,8$ & 808 & 314 & 38,9 & $2.151,2$ & 924 & 386 & 41,8 & $6.894,0$ \\
\hline 2004 & 129 & 88 & 68,2 & $5.972,3$ & 868 & 314 & 36,2 & $2.498,2$ & 997 & 402 & 40,3 & $8.470,5$ \\
\hline 2005 & 120 & 82 & 68,3 & $7.065,5$ & 835 & 316 & 37,8 & $2.347,1$ & 955 & 398 & 41,7 & $9.412,6$ \\
\hline
\end{tabular}


zembro de 2005. Já em 2005, 68,3\% das 120 empresas, ou seja, 82 das pesquisadas pagaram os JSCP aos seus acionistas num volume equivalente a 7.065,5 milhões de dólares, o que representa quase 11 vezes o valor pago em 1996. Pelo comportamento dos últimos anos, pode-se concluir que, atualmente, de cada três das empresas componentes desse grupo, duas têm feito a opção de pagar JSCP.

No grupo de empresas que não têm suas ações negociadas em Bolsa a adesão tem se mostrado bastante menor. No início, em 1996, 12,1\% das 396 empresas que apresentaram lucro fizeram o referido pagamento ou crédito. Em 2005, das 835 empresas que apresentaram lucro apenas
316 pagaram ou creditaram JSCP aos seus sócios e acionistas. Do ponto de vista relativo esse número de empresas é, praticamente, o triplo daquele que fez a opção em 1996, mas, atualmente, apenas 38\% das empresas vêm utilizando a opção oferecida pela legislação. Em 2005, em valores absolutos, esse grupo de empresas pagou o equivalente a 2.347,1 milhões de dólares, o que representa 5 vezes o valor pago em 1996. O Gráfico 10 demonstra a evolução percentual da quantidade de empresas, com em sem ações na bolsa, que tem optado pelo pagamento dos JSCP.

A Tabela 40 classifica as empresas pela origem do capital e as classifica em nacionais, estrangeiras e estatais.

Empresas que pagaram/creditaram JSCP Forma de distribuição do capital (em \%)

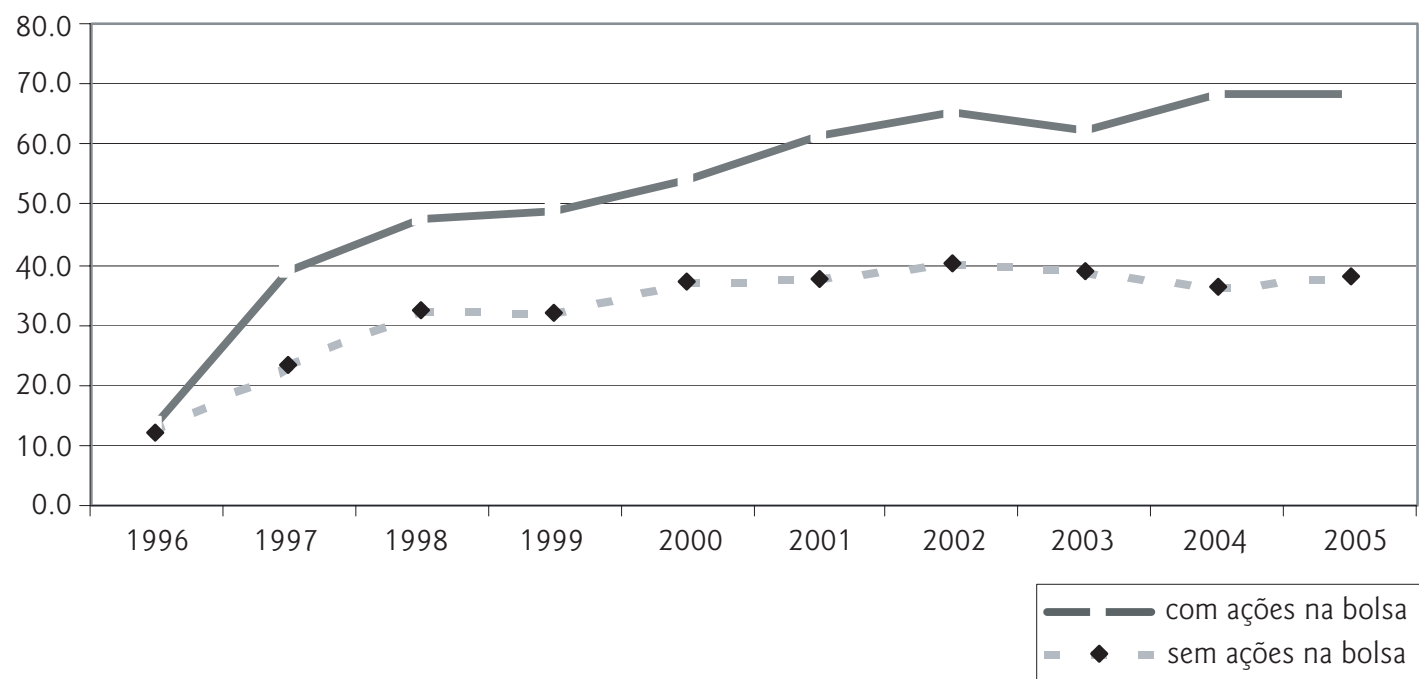

Gráfico 1 Análise pela natureza do capital das empresas

Tabela 4 || Empresas Nacionais, Estrangeiras e Estatais

Empresas cuja forma de tributação $=$ Lucro Real

em US \$ milhões - 31/12/2005

\begin{tabular}{|c|c|c|c|c|c|c|c|c|c|c|c|c|}
\hline \multirow{3}{*}{ Ano } & \multicolumn{4}{|c|}{ Nacionais } & \multicolumn{4}{|c|}{ Estrangeiras } & \multicolumn{4}{|c|}{ Estatais } \\
\hline & \multirow{2}{*}{$\begin{array}{l}\text { Quanti- } \\
\text { dade de } \\
\text { empresas } \\
\text { c/ lucro }\end{array}$} & \multicolumn{3}{|c|}{$\begin{array}{c}\text { Informações sobre } \\
\text { empresas que pagaram/ } \\
\text { creditaram JSCP }\end{array}$} & \multirow{2}{*}{$\begin{array}{l}\text { Quanti- } \\
\text { dade de } \\
\text { empresas } \\
\text { c/ lucro }\end{array}$} & \multicolumn{3}{|c|}{$\begin{array}{c}\text { Informações sobre } \\
\text { empresas que pagaram/ } \\
\text { creditaram JSCP }\end{array}$} & \multirow{2}{*}{$\begin{array}{l}\text { Quanti- } \\
\text { dade de } \\
\text { empresas } \\
\text { c/ lucro }\end{array}$} & \multicolumn{3}{|c|}{$\begin{array}{c}\text { Informações sobre } \\
\text { empresas que pagaram/ } \\
\text { creditaram JSCP }\end{array}$} \\
\hline & & $\begin{array}{l}\text { Quanti- } \\
\text { dade de } \\
\text { empresas }\end{array}$ & $\%$ & $\begin{array}{c}\text { US\$ } \\
\text { milhões }\end{array}$ & & $\begin{array}{l}\text { Quanti- } \\
\text { dade de } \\
\text { empresas }\end{array}$ & $\%$ & $\begin{array}{c}\text { US\$ } \\
\text { milhões }\end{array}$ & & $\begin{array}{l}\text { Quanti- } \\
\text { dade de } \\
\text { empresas }\end{array}$ & $\%$ & $\begin{array}{c}\text { US\$ } \\
\text { milhões }\end{array}$ \\
\hline 1996 & 407 & 46 & 11,3 & 497,5 & 53 & 13 & 24,5 & 583,6 & 33 & 2 & 6,1 & 18,5 \\
\hline 1997 & 440 & 105 & 23,9 & $1.477,8$ & 63 & 26 & 41,3 & 855,5 & 32 & 8 & 25,0 & 855,8 \\
\hline 1998 & 474 & 160 & 33,8 & $2.744,0$ & 83 & 37 & 44,6 & $1.231,6$ & 29 & 9 & 31,0 & $1.680,0$ \\
\hline 1999 & 476 & 164 & 34,5 & $2.012,8$ & 92 & 37 & 40,2 & $1.504,0$ & 31 & 7 & 22,6 & 286,6 \\
\hline 2000 & 551 & 220 & 39,9 & $3.598,9$ & 138 & 56 & 40,6 & $2.026,4$ & 35 & 13 & 37,1 & 828,0 \\
\hline 2001 & 567 & 227 & 40,0 & $3.205,5$ & 130 & 62 & 47,7 & $2.097,6$ & 38 & 13 & 34,2 & 846,3 \\
\hline 2002 & 594 & 247 & 41,6 & $2.613,0$ & 122 & 60 & 49,2 & $1.233,5$ & 28 & 13 & 46,4 & 532,0 \\
\hline 2003 & 695 & 285 & 41,0 & $3.678,5$ & 180 & 78 & 43,3 & $2.153,0$ & 49 & 23 & 46,9 & $1.062,6$ \\
\hline 2004 & 742 & 292 & 39,4 & $3.646,4$ & 199 & 82 & 41,2 & $2.101,8$ & 56 & 28 & 50,0 & $2.722,2$ \\
\hline 2005 & 688 & 272 & 39,5 & $3.487,0$ & 207 & 97 & 46,9 & $2.364,0$ & 60 & 29 & 48,3 & $3.561,6$ \\
\hline
\end{tabular}


Nessa forma de classificação, o que se pode constatar é que, em 2005, as estatais e as estrangeiras formaram os conjuntos que tiveram, proporcionalmente, as maiores quantidade de empresas que efetuaram pagamentos ou créditos aos seus acionistas a título de JSCP. Outro fato que chama a atenção é que, em 1996, primeiro ano de aplicação da legislação, apenas duas, dentre as 33 empresas estatais pesquisadas, efetuaram referido pagamento ou crédito. Em 2005, 29 das 60 empresas estatais pesquisadas, aproximadamente $48 \%$, decidiram pagar ou creditar os JSCP aos seus acionistas. O volume pago, nesse ano, foi equivalente a 3.561,6 milhões de dólares.

Em valores absolutos, as empresas nacionais pagaram, em 2005, o equivalente a 3.487,0 milhões de dólares e isso representa 7,0 vezes o valor de 1996. Nesse ano, a quantidade de empresas nacionais que optaram por fazer esse pagamento era equivalente a $11,3 \%$ das empresas que tinham apresentado lucro; essa proporção cresceu, em 2005 , para $39,5 \%$.

As 97 empresas estrangeiras que optaram por fazer tal pagamento em 2005 representavam 46,9\% das pesquisadas; em 1996, essa relação era de $24,5 \%$. Em valores absolutos, o valor pago, equivalente a 2.364,0 milhões de dólares, representou 4,1 vezes o montante de 1996. A evolução percentual da quantidade de empresas nacionais, estrangeiras e estatais, que optaram pelo pagamento dos JSCP no período 1996 a 2005, é apresentada no Gráfico 20.

A Tabela 50 apresenta os dados das empresas classificadas por ramo de atividade.

Em 1996, proporcionalmente à quantidade de empresas, o ramo de serviços, com apenas 6,7 \% das empresas pesquisadas, foi o que teve a menor adesão ao pagamento dos JSCP. Em 2005, a decisão de efetuar o referido pagamento foi tomada por $40,0 \%$ das empresas pesquisadas e isso atingiu, praticamente, o mesmo nível das empresas comerciais, com $41,0 \%$, ou das indústrias com $42,9 \%$.

Em valores absolutos, o ramo de serviços, também, foi o que apresentou maior evolução; em 2005, pagou o equivalente a 3.088,0 milhões de dólares, o que representa 24,1 vezes o valor de 1996. De outro lado, as empresas comerciais foram as que apresentaram menor evolução nesses pagamentos; o valor de 2005 representa apenas 1,7 vezes o valor pago em 1996. As empresas industriais, com o equivalente a 6.058,1 milhões de dólares pagos em 2005, também apresentaram crescimento bastante razoável, pois o valor dos pagamentos de 1996 totalizou o equivalente a 814,8 milhões de dólares. O Gráfico 3 indica a evolução percentual, por ramo de atividade, para o período de 1996 a 2005, das empresas que optaram pelo pagamento dos JSCP.

Empresas que pagaram/creditaram JSCP

Origem do capital (em \%)

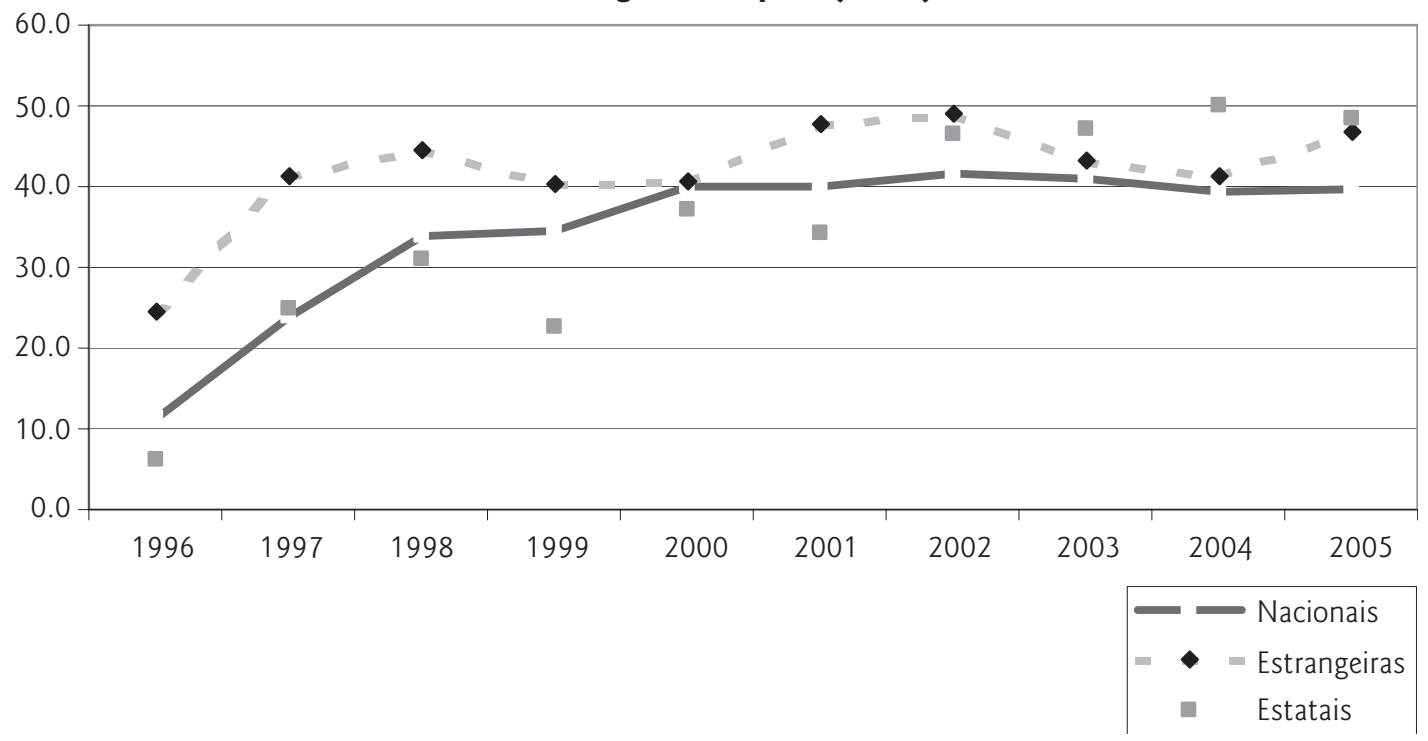

Gráfico 2 Análise pela origem do capital das empresas 
Tabela 5 | Indústria, Comércio e Serviços

Empresas cuja forma de tributação = Lucro Real

em US\$ milhões - 31/12/2005

\begin{tabular}{|c|c|c|c|c|c|c|c|c|c|c|c|c|}
\hline \multirow{3}{*}{ Ano } & \multicolumn{4}{|c|}{ Indústria } & \multicolumn{4}{|c|}{ Comércio } & \multicolumn{4}{|c|}{ Serviços } \\
\hline & \multirow{2}{*}{$\begin{array}{l}\text { Quanti- } \\
\text { dade de } \\
\text { empresas } \\
\text { c/ lucro }\end{array}$} & \multicolumn{3}{|c|}{$\begin{array}{c}\text { Informações sobre } \\
\text { empresas que pagaram/ } \\
\text { creditaram JSCP }\end{array}$} & \multirow{2}{*}{$\begin{array}{l}\text { Quanti- } \\
\text { dade de } \\
\text { empresas } \\
\text { c/ lucro }\end{array}$} & \multicolumn{3}{|c|}{$\begin{array}{c}\text { Informações sobre } \\
\text { empresas que pagaram/ } \\
\text { creditaram JSCP }\end{array}$} & \multirow{2}{*}{$\begin{array}{l}\text { Quanti- } \\
\text { dade de } \\
\text { empresas } \\
\text { c/ lucro }\end{array}$} & \multicolumn{3}{|c|}{$\begin{array}{c}\text { Informações sobre } \\
\text { empresas que pagaram/ } \\
\text { creditaram JSCP }\end{array}$} \\
\hline & & $\begin{array}{l}\text { Quanti- } \\
\text { dade de } \\
\text { empresas }\end{array}$ & $\%$ & $\begin{array}{c}\text { US\$ } \\
\text { milhões }\end{array}$ & & \begin{tabular}{|c|} 
Quanti- \\
dade de \\
empresas
\end{tabular} & $\%$ & $\begin{array}{c}\text { US\$ } \\
\text { milhões }\end{array}$ & & $\begin{array}{l}\text { Quanti- } \\
\text { dade de } \\
\text { empresas }\end{array}$ & $\%$ & $\begin{array}{c}\text { US\$ } \\
\text { milhões }\end{array}$ \\
\hline 1996 & 325 & 42 & 12,9 & 814,8 & 78 & 13 & 16,7 & 156,6 & 90 & 6 & 6,7 & 128,3 \\
\hline 1997 & 343 & 83 & 24,2 & $1.768,7$ & 91 & 31 & 34,1 & 273,3 & 101 & 25 & 24,8 & $1.147,1$ \\
\hline 1998 & 340 & 108 & 31,8 & $2.316,6$ & 114 & 39 & 34,2 & 357,2 & 132 & 59 & 44,7 & $2.981,8$ \\
\hline 1999 & 371 & 122 & 32,9 & $2.072,1$ & 95 & 37 & 38,9 & 225,0 & 133 & 49 & 36,8 & $1.506,2$ \\
\hline 2000 & 433 & 169 & 39,0 & $3.543,4$ & 113 & 48 & 42,5 & 334,6 & 178 & 72 & 40,4 & $2.575,2$ \\
\hline 2001 & 420 & 165 & 39,3 & $3.206,6$ & 118 & 51 & 43,2 & 204,6 & 197 & 86 & 43,7 & $2.738,2$ \\
\hline 2002 & 442 & 189 & 42,8 & $2.463,9$ & 125 & 58 & 46,4 & 196,4 & 177 & 73 & 41,2 & $1.718,2$ \\
\hline 2003 & 546 & 215 & 39,4 & $3.916,4$ & 144 & 68 & 47,2 & 221,2 & 234 & 103 & 44,0 & $2.756,4$ \\
\hline 2004 & 576 & 228 & 39,6 & $5.797,2$ & 147 & 60 & 40,8 & 269,4 & 274 & 114 & 41,6 & $2.403,9$ \\
\hline 2005 & 504 & 216 & 42,9 & $6.058,1$ & 161 & 66 & 41,0 & 266,6 & 290 & 116 & 40,0 & $3.088,0$ \\
\hline
\end{tabular}

Empresas que pagaram/creditaram JSCP

Ramo de atividade (em \%)

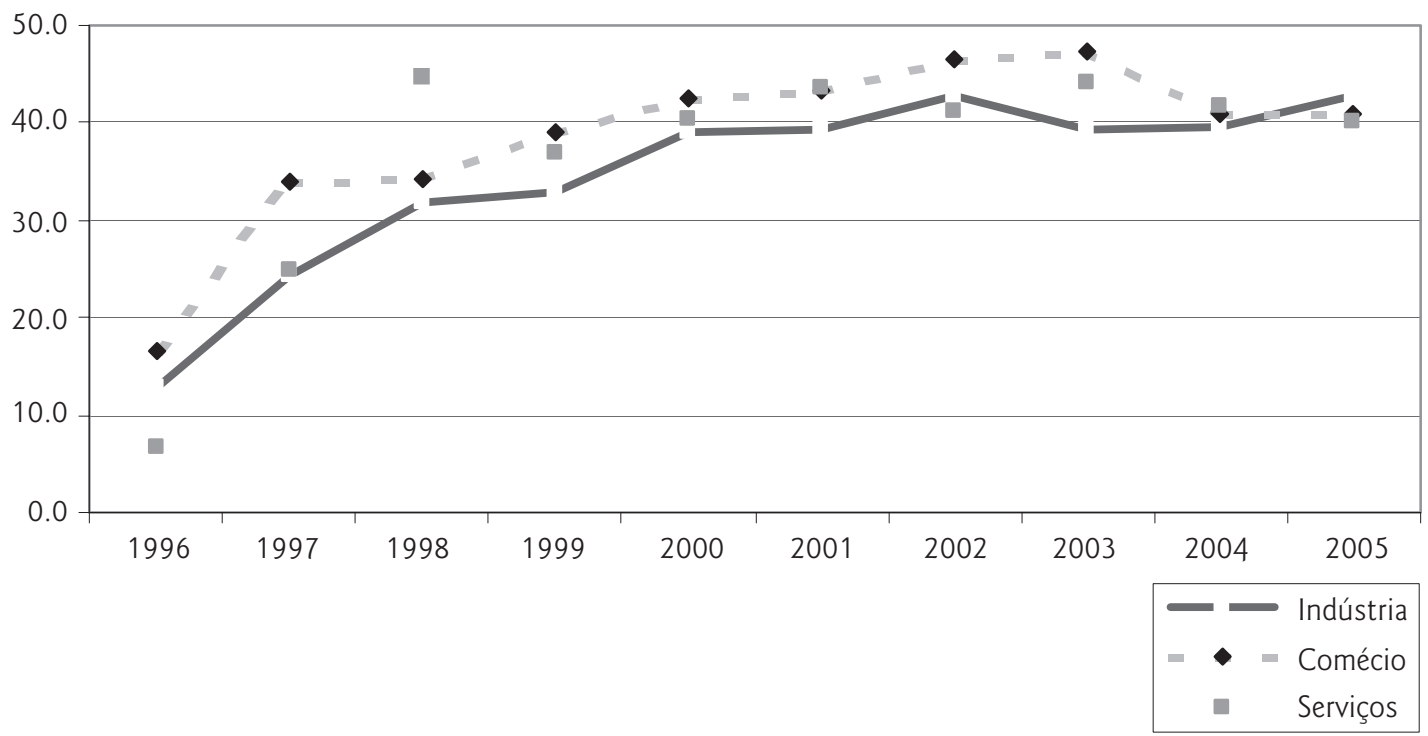

Gráfico 3 Análise pelo ramo de atividades das empresas

\section{CONSIDERAÇÕES FINAIS E CONCLUSÕES}

Ao longo deste trabalho, as principais conclusões $e$ observações foram sendo apontadas. A seguir, serão apresentados os principais assuntos tratados e a indicação de algumas das conclusões mais importantes, principalmente as respostas às questões inicialmente propostas.

A Lei 9.249, promulgada em 1995, criou a possibilidade de as empresas remunerarem seus acionistas através dos pagamentos ou créditos de Juros Sobre o Capital Próprio - JSCP. Tais pagamentos, efetuados de forma opcional, podem ser considerados como despesas dedutíveis no cálculo do imposto de renda e da contribuição social incidentes sobre os lucros das empresas. Essa inovação fiscal veio acompanhada de duas outras importantes novidades: a) redução das alíquotas de imposto de renda e contribuiç̧ão social incidentes sobre os lucros das empresas; b) eliminação dos efeitos da inflação nas demonstrações contábeis.

Infelizmente, mesmo com a drástica redução de nossos índices inflacionários, os níveis de preços continuaram 
sofrendo aumentos. A inflação oficial não reconhecida nas demonstrações contábeis, no período de 1996 a 2005, já ultrapassa a casa dos $103 \%$.

O trabalho de pesquisa considerou, em amostra não aleatória, as demonstrações contábeis apresentadas pelas empresas no período de 1996 a 2005. No primeiro ano, 1996, foram analisadas 493 demonstrações e, em 2005. último ano da pesquisa, as demonstrações utilizadas somaram 955 empresas.

Os resultados mostraram que, dentre as empresas pesquisadas, aproximadamente $42 \%$ delas têm utilizado a alternativa do pagamento ou crédito aos seus sócios e acionistas na forma de juros sobre o capital próprio. Também ficou constatado que a distribuição desses 42\% de empresas é bastante equilibrada entre as empresas industriais, comerciais e de prestação de serviços. O grande desequilíbrio ficou por conta da segregação feita entre empresas com e sem ações na Bolsa. Enquanto de cada três empresas com ação na Bolsa duas pagam JSCP, entre as que não têm ação na Bolsa de cada três apenas uma efetua o pagamento referido. Finalmente as empresas foram segregadas, de acordo com a origem de seus respectivos capitais, em nacionais, estrangeiras e estatais. Nesse grupamento, os destaques ficaram para as empresas estatais e estrangeiras, que, praticamente, de cada duas empresas pesquisadas uma remunera seus acionistas na forma de JSCP.

\section{Referências Bibliográficas}

ATKINSON, A. A.; BANKER, R. D.; KAPLAN, R. S.; YOUNG. S. M.. Contabilidade Gerencial. Tradução de André Olímpio M. C. Castro. São Paulo: Atlas, 2000.

BRASIL. Lei no 6.404 , de 15 de dezembro de1976.

BRASIL. Lei no 7.799 , de 10 de julho de 1989.

BRASIL. Lei no 9.249, de 26 de dezembro de 1995 .

LIPSEY, R. G.; STEINER, P. O.. Economics, 2. ed. New York: Harper \& Row, 1969.

MARTINS, Eliseu. Um pouco da história dos Juros sobre o capital próprio. Temática contábil e balanços - IOB, Bol. 49/2004.

. Juros sobre o capital próprio - aspectos conceituais. Temática contábil e balanços - IOB, v. 50, p. 515-507, 1996.

. Extinção da correção monetária - os juros sobre o capital próprio (TJLP) e os dividendos (1ª. parte). Temática contábil e

balanços-IOB, p. 433-426, 1996.

MARTINS, Gilberto de Andrade. Manual para elaboração de monografias e dissertações. 2. ed. São Paulo: Atlas, 1994

SELLTIZ, Claire et alii. Métodos de pesquisa nas relações sociais. São Paulo: Herder/EPU, 1974.

STEVENSON, William J.. Estatística aplicada à administração. São Paulo: Harbra, 1986.

TOLEDO, Geraldo Luciano; OVALLE, Ivo Izidoro. Estatística básica. 2 ed. São Paulo: Atlas, 1989.

\section{Bibliografia Complementar}

ANTHONY, Robert N. Equity interest - Its time has come. Journal of Accountancy (pre 1986); Dec 1982; ABI/INFORM Global p. 76.

ANTHONY, Robert N. Recognizing the cost of interest on equity. Harvard Business Review. Boston: Jan/Feb 1982. Vol. 60, N. 1; p. 91-97.

ARCADY, Alex T. e BAKER, Charles L.. Interest cost accounting. Some practical guidance. Journal of Accountancy (pre 1986); May 1981; ABI/ INFORM Global p. 62.

BRASIL. Instrução Normativa SRF no 11, de 21 de fevereiro de 1996.

BRASIL. Deliberação CVM no 207, de 13 de dezembro de 1996.

BRASIL. Lei no 9.430, de 27 de dezembro de 1996.

BRASIL. Instrução Normativa SRF no 41, de 22 de abril de 1998.

BRASIL. Instrução Normativa SRF no 12, de 10 de fevereiro de 1999.

BRASIL. Decreto no 3.000, de 26 de março de 1999.

CASTILLO, Nicasio; SALERNO, John A.. Taking advantage of tax treaties in Latin America. International Tax Review. London: Mar 2003 , p. 1.

DRURY, Colin; TAYLEST, Mike. Issues arising from surveys of management accounting practices. Management Accounting Research, vol. 6 , $\mathrm{p}$. 267-280, 1995

FIPECAFI. Manual de contabilidade das sociedades por ações. 6. ed. São Paulo: Atlas, 2003.

GRAHAM, John R.. How big are the tax benefits of debt? The Journal of Finance. V. 55, Oct. 2000. 
HENDRIKSEN, Eldon S.; BREDA, Michael F. V.. Teoria da contabilidade. Tradução de Antonio Z. Sanvicente. São Paulo: Atlas, 1999.

HIGUCHI, Hiromi; HIGUCHI, Celso H.. Imposto de renda das empresas: interpretação e prática. 29a. ed. São Paulo: Atlas, 2003.

IUDÍCIBUS, Sérgio de. Teoria da contabilidade. 5. ed. São Paulo: Atlas, 1997.

jun.1990.

Utilização de Informações Contábeis para Finalidades Econômicas. Boletim do Contador - Ibracon. São Paulo, n. 145,

LAKATOS, Eva Maria; MARCONI, Marina de Andrade. Metodologia científica, São Paulo: Atlas, 1982.

MACKIE-MASON, Jeffrey. Do taxes affect corporate financing decisions? The Journal of Finance, v. 45, May, 1977.

MARTINS, Gilberto A.; PINTO, Ricardo Lopes. Manual par elaboração de trabalhos acadêmicos. São Paulo: Atlas, 2001.

MODIGLIAN, Franco; MILLER, Merton H.. The cost of capital, corparate finance and theory of investiment. American Economic Review, v.48, p. 261-267, June, 1958.

MUNARETTO, Lorimar F.. Uma análise comparativa dos tributos e contribuições incidentes sobre o pró-labore, dividendos e juros sobre o capital próprio. Revista do CRC-RS, n. 114, out., 2003.

NESS Jr., W. L.; ZANI, João. Os juros sobre o capital próprio versus a vantagem fiscal do endividamento. Revista de Administração - RAUSP, v. 36, p. 89-102, abril/junho, 2001.

PRATT, Shanon P.. Cost of Capital: estimation and applications. New York: John Wiley \& Sons. Inc., 1998.

ROSS, Stephen A.; WESTERFIELD, Randolph W.; JAFFE, Jeffrey F. Administração financeira. Tadução de Antonio Z. Sanvicente. São Paulo: Atlas, 1995.

SCOFIELD, Barbara W.. Full disclosure of interest.capitalization decisions. The National Public Accountant; Apr 1994; ABI/INFORM Global p. 20.

SCHMITT, Francisco O. V.. Os determinantes da estrutura de capitais das empresas brasileiras. 2004. Tese (Doutoramento). Faculdade de Economia, Administração e Contabilidade. Universidade de São Paulo, São Paulo.

WELLS, Bret; WILCZYNSKI, Mike. Tax-effective methods to finance Latin Amercian operations. The International Tax Journal: Summer 2002; ABI/INFORM Global p. 21.

ZANI, João. Estrutura de capital: avaliação do impacto dos juros sobre o capital próprio na decisão do financiamento dos investimentos. 1999. Dissertação. (Mestrado). Pontifícia Universidade Católica do Rio de Janeiro e Universidade do Vale do Rio dos Sinos, São Leopoldo, Rio Grande do Sul.

\section{NOTA - Endereço do autor}

Universidade de São Paulo

FEA- Departamento de Contabilidade e Atuária

Av. Prof. Luciano Gualberto, 908

São Paulo - SP

05508-900 